\title{
PENGARUH PEMERIKSAAN PAJAK TERHADAP PENERIMAAN PAJAK PADA KANTOR PELAYANAN PAJAK PRATAMA DI WILAYAH MAKASSAR UTARA
}

\author{
Muhammad Minsar \\ (STIE Wirabhakti Makassar)
}

\begin{abstract}
ABSTRAK
Penelitian ini bertujuan untuk menganalisis pengaruh audit pajak terhadap penerimaan pajak. Responden dalam penelitian ini adalah karyawan pajak (otoritas pajak) pada KPP Makassar Utara. Jumlah pejabat pajak yang menjadi sampel penelitian adalah 88 petugas pajak, layanan pajak, dan audit pajak. Metode pengambilan sampel yang digunakan dalam penelitian ini adalah convenience sampling, sedangkan metode pengolahan data yang digunakan adalah analisis regresi sederhana. Hasil penelitian menunjukkan bahwa penilaian pajak berpengaruh positif tetapi tidak signifikan terhadap penerimaan pajak.
\end{abstract}

Keywords: pemeriksaan pajak, penerimaan pajak

\section{PENDAHULUAN}

\section{Latar Belakang}

Sebagai negara yang berkembang, negara Indonesia harusnya memiliki berbagai macam potensi untuk menjadi negara yang lebih maju. Akan tetapi pada kenyataannya Indonesia belum dapat memanfaatkan berbagai potensi tersebut. Indonesia mengalami berbagai masalah hampir di semua sektor, salah satu yang terbesar ialah masalah di sektor ekonomi, untuk memperbaiki masalah tersebut maka pajak diharapkan bisa menjadi solusi yang efektif. Hal ini disebabkan karena pajak merupakan potensi penerimaan terbesar dalam negeri. pajak merupakan penerimaan langsung yang segera bisa diolah guna untuk pembiayaan berbagai macam keperluan negara.

Tata cara pemungutan pajak sebuah negara memerlukan sebuah sistem yang telah disetujui masyarakat melalui dewan perwakilan, dengan menghasilkan suatu perundang-undangan yang menjadi dasar pelaksanaan 
perpajakan bagi fiskus maupun bagi wajib pajak. Sistem pemungutan pajak yang berlaku di negara kita berdasarkan peraturan perundang-undangan perpajakan menuntut Wajib Pajak untuk turut aktif terhadap pemenuhan kewajiban perpajakannya. Sistem pemungutan yang berlaku di Indonesia yaitu Self Assessment System, di mana pemenuhan kewajiban perpajakan dilakukan sepenuhnya oleh Wajib Pajak.

Tujuan pemeriksaan pajak telah tercantum dalam Keputusan Menteri Keuangan Nomor 545/KMK.04/2000 tanggal 22 Desember 2000 untuk menguji kepatuhan pemenuhan kewajiban perpajakan dalam rangka memberikan kepastian hukum. Pemeriksaan tersebut untuk menguji kepatuhan wajib pajak dalam hal SPT menunjukkan kelebihan pembayaran pajak, termasuk yang telah diberikan pengembalian pendahuluan kelebihan pajak, SPT tahunan pajak penghasilan menunjukkan kerugian, SPT tidak disampaikan atau disampaikan tidak pada waktu yang telah ditetapkan, SPT yang memenuhi kriteria seleksi yang ditentukan oleh Direktur Jenderal Pajak.

Sementara di sisi lain, masih rendahnya tingkat kepatuhan menjadi sebuah masalah besar bagi pemerintah yang mempunyai target penerimaan perpajakan meningkat tiap tahun untuk membiayai kebutuhan belanja Negara. SPN pada dasarnya merupakan program ekstensifikasi yang baik dan proaktif. Sifat proaktif itu ditunjukkan dari petugas pajak yang mendatangi subjek pajak secara langsung di lokasi tempat usaha atau tempat tinggal wajib pajak. Sasarannya adalah wajib pajak pribadi atau perorangan. Petugas pajak melakukan pemeriksaan setiap rumah, khususnya perumahan mewah. Selain itu, petugas pajak juga akan mendatangi perkantoran, pusat perbelanjaan, pertokoan, dan dimungkinkan mendatangi pelaku usaha kecil dan menengah. Berdasarkan uraian diatas, maka penelitan ini fokus pada Pengaruh Pemeriksaan Pajak Terhadap Penerimaan Pajak Pada Kantor Pelayanan Pajak Pratama di Wilayah Makassar Utara.

\section{TELAAH LITERATUR DAN PENGEMBANGAN HIPOTESIS}

\section{Defenisi Pajak}

Pasal 1 UU No. 28 Tahun 2007 tentang ketentuan umum dan tata cara 
perpajakan: pajak adalah kontribusi wajib pada negara yang terutang oleh orang pribadi atau badan yang bersifat memaksa berdasarkan undangundang, dengan tidak mendapatkan imbalan secara langsung dan digunakan untukkeperluan negara bagi sebesar-besarnya kemakmuran rakyat.

Menurut Prof. Dr. Rochmat Soemitro pajak ialah iuran rakyat kepada negara (peralihan kekayaan dari sektor partikelir ke sektor pemerintah) berdasarkan undang-undang (dapat dipaksakan) dengan tiada mendapat jasa timbal balik (tegen prestise) yang langsung dapat ditunjuk dan yang digunakan untuk membiayai pengeluaran umum.

\section{Pemeriksaan Pajak}

Undang-undang yang mengatur Tentang Ketentuan Umum dan Tata Cara Perpajakan (Pasal 1 angka 24) dan juga (Pasal 1 ayat 1) Keputusan Menteri Keuangan No.545/KMK.04/2000 tanggal 22 Desember 2000 Tentang Tata Cara Pemeriksaan Pajak, dikatakan bahwa pemeriksaan pajak adalah serangkaian kegiatan untuk mencari, mengumpulkan, serta mengolah data dan/atau keterangan lainnya untuk menguji kepatuhan atas pemenuhan kewajiban perpajakan dan untuk tujuan lain dalam rangka melaksanakan ketentuan peraturan perundang-undangan perpapajakan.

Adapun ahli yang mengemukakan pendapat terkait dengan pemeriksaan pajak, diantaranya : Pengertian pemeriksaan menurut Undang-undang Nomor 28 Tahun 2007 dikutip dari Pardiat (2008:11) adalah sebagai berikut: "Pemeriksaan pajak adalah serangkaian kegiatan menghimpun dan mengolah data, keterangan dan/atau bukti yang dilaksanakan secara objektif dan profesional berdasarkan suatu standar pemeriksaan untuk menguji kepatuhan pemenuhan kewajiban perpajakan dan/atau untuk tujuan lain dalam rangka melaksanakan ketentuan peraturan perundang-undangan perpajakan.

\section{Penerimaan pajak}

Peran dari penerimaan pajak sangat penting bagi kemandirian negara, karena pajak merupakan salah satu sumber penerimaan negara dari dalam negeri yang paling utama selain dari minyak dan gas bumi untuk mendanai Anggaran Pendapatan dan Belanja Negara (APBN). 
Dilihat dari sisi ekonomi, penerimaan dari sektor pajak merupakan penerimaan negara yang potensial, karena melalui pajak pemerintah dapat membiayai sarana dan prasarana publik diseluruh sektor kehidupan, seperti sarana transportasi, air, listrik, pendidikan, kesehatan, keamanan, komunikasi, sosial dan berbagai fasilitas lainnya yang ditujukan untuk memenuhi kebutuhan pembangunan.

\section{METODE PENELITIAN}

Penelitian ini di lakukan di kantor pelayanan Pajak Pratama Makassar utara di Jl. Urip Sumoharjo KM 4 GKN 1. Makassar 441259. Populasi dalam penelitian ini adalah pegawai atau karyawan pelayanan pajak yang bekerja di KPP Pratama Makassar Utara. Pemilihan sampel dilakukan dengan menggunakan metode sensus. Berdasarkan data yang diperoleh jumlah total pegawai yang bekerja di KPP Makassar Utara adalah sebanyak 88 orang.

\section{HASIL PENELITIAN DAN PEMBAHASAN}

Jumlah kuesioner yang disebar adalah sebanyak 88 kuesioner langsung kepada responden yang bertugas di Kantor Pelayanan Pajak Pratama wilayah Makassar Utara.

Tabel 1. Data distribusi sampel penelitian

\begin{tabular}{|l|l|l|l|l|}
\hline No. & Nama KPP Pratama & Alamat & $\begin{array}{l}\text { Kuesioner } \\
\text { yang } \\
\text { dibagikan }\end{array}$ & $\begin{array}{l}\text { Kuesioner yang } \\
\text { dikembalikan }\end{array}$ \\
\hline 1. & $\begin{array}{l}\text { KPP pratama } \\
\text { Makassar Utara }\end{array}$ & $\begin{array}{l}\text { Jl. Urip } \\
\text { Sumoharjo KM. 4 } \\
\text { Gedung } \\
\text { Keuangan } \\
\text { Negara 1 }\end{array}$ & 88 & 84 \\
& & & \\
\hline
\end{tabular}

Sumber : Data Primer yang diolah, 2019

Kuesioner yang disebarkan berjumlah 88 kuesioner dan jumlah kuesioner yang kembali adalah sebanyak 84 kuesioner atau 95\%. Kuesioner yang dapat diolah berjumlah 84 Kuesioner atau 95\%.

Tabel 2. Sampel penelitian

\begin{tabular}{|l|l|l|l|}
\hline No. & Keterangan Kuesioner & Jumlah & Persentase \% \\
\hline 1. & Kuesioner yang disebar & 88 & 100 \\
\hline 2. & Kuesioner yang kembali & 84 & 95 \\
\hline
\end{tabular}




\begin{tabular}{|l|l|l|l|}
\hline 3. & Kuesioner yang tidak kembali & 4 & 5 \\
\hline 4. & Kuesioner yang dapat diolah & 84 & 95 \\
\hline
\end{tabular}

Sumber : Data Primer yang diolah, 2019

\section{Hasil Pengujian Uji Asumsi Klasik}

\section{a. Uji Normalitas}

Gambar 1. Hasil Uji Normalitas

Normal P-P Plot of Regression Standardized
Residual

Dependent Variable: Penerimaan Pajak

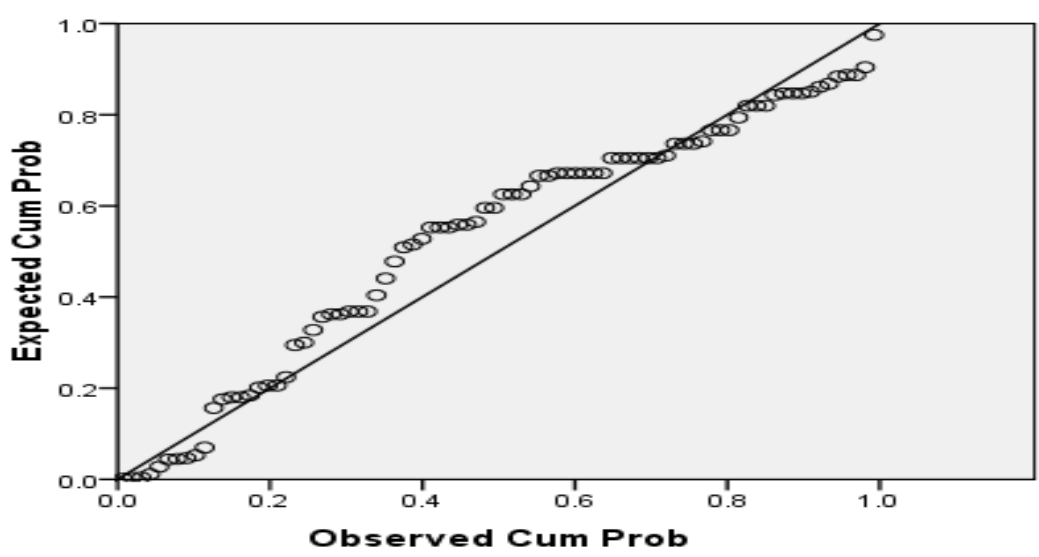

Gambar Sumber : Data Primer yang diolah 2019

Berdasarkan grafik normal plot pada gambar 1. menunjukkan bahwa model regresi layak dipakai dalam penelitian ini karena pada grafik normal plot terlihat titik-titik menyebar disekitar garis diagonal serta penyebarannya mengikuti arah garis diagonal sehingga memenuhi asumsi normalitas.

\section{Hasil Uji Regresi Linier Sederhana}

Tabel 3. Hasil Uji Regresi Linier Sederhana

\begin{tabular}{|c|c|c|c|c|c|c|}
\hline \multicolumn{7}{|c|}{ Coefficients $^{a}$} \\
\hline & & \multicolumn{2}{|c|}{$\begin{array}{l}\text { Unstandardized } \\
\text { Coefficients }\end{array}$} & $\begin{array}{c}\text { Standardized } \\
\text { Coefficients }\end{array}$ & \multirow[b]{2}{*}{$\mathrm{t}$} & \multirow[b]{2}{*}{ Sig. } \\
\hline \multicolumn{2}{|c|}{ Model } & $B$ & Std. Error & Beta & & \\
\hline & (Constant) & 12.272 & 3.159 & & 3.884 & .000 \\
\hline & Pemeriksaan & .194 & .055 & .365 & 3.552 & .001 \\
\hline & Pajak & & & & & \\
\hline
\end{tabular}




\begin{tabular}{|c|c|c|c|c|c|c|}
\hline \multicolumn{7}{|c|}{ Coefficients $^{a}$} \\
\hline \multirow{2}{*}{\multicolumn{2}{|c|}{ Model }} & \multicolumn{2}{|c|}{$\begin{array}{c}\text { Unstandardized } \\
\text { Coefficients }\end{array}$} & \multirow{2}{*}{\begin{tabular}{|c|}
$\begin{array}{c}\text { Standardized } \\
\text { Coefficients }\end{array}$ \\
Beta
\end{tabular}} & \multirow[b]{2}{*}{$\mathrm{t}$} & \multirow[b]{2}{*}{ Sig. } \\
\hline & & B & Std. Error & & & \\
\hline \multirow[t]{2}{*}{1} & (Constant) & 12.272 & 3.159 & & 3.884 & .000 \\
\hline & $\begin{array}{l}\text { Pemeriksaan } \\
\text { Pajak }\end{array}$ & .194 & .055 & .365 & 3.552 & .001 \\
\hline
\end{tabular}

a. Dependent Variable: Penerimaan Pajak

Sumber : Data primer yang diolah, 2019

Berdasarkan tabel 3. Diketahui bahwa nilai koefisien dari persamaan regresi dari output didapatkan model persamaan regresi sebagai berikut:

\section{$Y=a+b X$}

Dimana

$$
\begin{aligned}
& \mathrm{Y}=\text { Penerimaan Pajak } \\
& \mathrm{a}=\text { konstanta } \\
& \mathrm{b}=\text { koefisien regresi } \\
& \mathrm{X}=\text { Pemeriksaan pajak }
\end{aligned}
$$

Maka diperoleh hasil regreasi linier sederhana ialah :

$$
Y=12.272+0.194 X
$$

Kemudian dapat diiterpretasikan bahwa :

Koefisien regresi variabel pemeriksaan pajak $(X)$ sebesar 0.194 yang artinya jika pemeriksaan pajak mengalami kenaikan $1 \%$ maka penerimaan pajak akan mengalami peningkatan sebesar 0.194.

Uji Koefisien Determinasi $\left(\mathbf{R}^{2}\right)$

Tabel 4. Hasil Uji Koefisien Determinasi $\left(\mathrm{R}^{2}\right)$

\begin{tabular}{|l|r|r|r|r|}
\hline \multicolumn{5}{|c|}{ Model Summary $^{\text {D }}$} \\
\hline Model & $\mathrm{R}$ & $\mathrm{R}$ Square & $\begin{array}{c}\text { Adjusted R } \\
\text { Square }\end{array}$ & $\begin{array}{r}\text { Std. Error of } \\
\text { the Estimate }\end{array}$ \\
\hline 1 & $.365^{\mathrm{a}}$ & .133 & .123 & 2.064 \\
\hline \multicolumn{5}{|l|}{ a. Predictors: (Constant), Pemeriksaan Pajak } \\
\hline
\end{tabular}


Berdasarkan tabel 4. diperoleh nilai Adjusted $\mathrm{R}^{2}$ sebesar 0.123. hal ini menunjukkan bahwa persentase pengaruh variabel independen (pemeriksaan pajak) terhadap variabel dependen (penerimaan pajak) sebesar $12.3 \%$ sedangkan sisanya $87.7 \%$ dipengaruhi oleh faktor lain yang tidak termasuk dalan penelitian ini seperti variabel kesadaran masyarakat (Suryadi, 2006), inflasi dan tingkat kepatuhan wajib pajak (Muiz, 2012).

Sedangkan hasil perhitungan dengan menggunakan analisis regresi diperoleh koefisien regresi variabel pemeriksaan pajak (X) sebesar 0.194 yang artinya jika pemeriksaan pajak mengalami kenaikan $1 \%$ maka penerimaan pajak akan mengalami peningkatan sebesar 0.194 . Hal ini berarti bahwa pemeriksaan pajak berpengaruh positif namun signifikan terhadap penerimaan pajak.

\section{Pembabahasan Hasil Penelitian}

Berdasarkan hasil penelitian yang telah dilakukan, diketahui bahwa persentase pengaruh variabel yang diteliti yaitu pemeriksaan pajak mempunyai pengaruh positif namun tidak signifikan terhadap penerimaan pajak. Hal ini menunjukkan bahwa pemeriksaan pajak dapat mempengaruhi Wajib Pajak untuk membayar kewajibannya, namun pengaruh yang ditimbulkan dari pemeriksaan pajak belum dapat mengoptimalkan penerimaan pajak. Hal ini disebabkan oleh faktor lain yang tidak diteliti pada penelitian ini.

Dari hasil penelitian dan ulasan di atas maka dapat dikatakan bahwa hipotesis yang dikemukakan oleh peneliti yaitu "apakah terdapat pengaruh signifikan antara pemeriksaan pajak dengan penerimaan pajak" ditolak, karena dalam penelitian ini tidak ditemukan adanya pengaruh yang signifikan antara pemeriksaan pajak dengan penerimaan pajak.

Pada penelitian terdahulu yang menjadi rujukan bagi peneliti, menunjukkan bahwa dengan dilakukannya pemeriksaan pajak oleh petugas pemeriksa pajak itu belum cukup untuk membuat para Wajib Pajak untuk mau membayar kewajiban perpajakannya. Seperti penelitian yang dilakukan oleh Irna Febrianti (2013) yang meneliti pengaruh kewajiban kepemilikan NPWP, pemeriksaan pajak dan penagihan pajak terhadap penerimaan pajak 
yang menemukan adanya keterkatian yang positif dan signifikan diantara semua variabel. Kemudian ada pula penelitian yang dilakukan oleh Ellya Florentin Listyaningtyas (2010) yang meneliti tentang efektivitas pelaksanaan pemeriksaan dalam rangka meningkatkan penerimaan Negara dari sektor pajak, yang menunjukkan bahwa pemeriksaan pajak dan surat paksa berpengaruh secara stimultan terhadap penerimaan pajak. Dari poin tersebut peneliti dapat menarik kesimpulan bahwa strategi penerapan pemeriksaan pajak harus dibarengi oleh beberapa strategi lainnya seperti dengan penagihan pajak, surat paksa sehingga dapat membuat para Wajib Pajak menjadi patuh untuk membayar kewajiban perpajakannya.

Pemeriksaan pajak yang dilakukan oleh petugas pemeriksa pajak sebenarnya mampu untuk mempengaruhi wajib pajak untuk membayar kewajibannya, namun seperti yang telah diuraikan sebelumnya bahwa dari segi efektivitasnya belum mampu memberikan dampak signifikan terhadap penerimaan pajak di KPP Pratama Makassar Utara. Tidak terdapat pengaruh antara pemeriksaan pajak terhadap peningkatan penerimaan pajak atau menurunnya penerimaan pajak dikarenakan rendahnya kesadaran masyarakat akan kewajiban perpajakannya, sanksi perpajakan yang sudah ataupun belum dilunasi oleh Wajib Pajak dan beberapa hal lainnya. Biaya pemeriksaan yang besar bisa menghambat aparat untuk melakukan pemeriksaan dan tidak ada biaya yang masuk atau pemeriksaan yang tidak menghasilkan juga dapat menurunkan penerimaan pajak. Pemeriksaan pajak merupakan upaya untuk mengantisipasi kemungkinan terjadinya penyelewengan oleh wajib pajak yang telah diberi kepercayaan self assessment agar peraturan perpajakan dapat dilakukan sebagaimana mestinya.

Masalah deskriptif lain dalam penerimaan pajak yang lainnya adalah karena dan pemeriksaan belum baik, hal ini terbukti dari hasil penelitian masih adanya pemeriksa yang kurang tertib dalam menjalankan tugasnya, sehingga hasil temuan kurang maksimal yang menyebabkan penerimaan pajak juga kurang dan menurun. Permasalahan kedua yaitu kurangnya data informasi baik eksternal maupun internal mengenai wajib pajak tertentu 
sehingga petugas pemeriksa pajak kesulitan untuk mengenakan pajak karena kurangya data wajib pajak yang kurang valid.

Pemeriksaan pajak yang berpengaruh positif terhadap penerimaan pajak di KPP Pratama Makassar Utara merupakan petunjuk bahwa penerapan Self Assessment System di KPP Pratama Makassar Uatara dalam hal pemenuhan kewajiban perpajakan terutama dalam mengisi Surat Pemberitahuan (SPT) sudah cukup baik. Hasil pengujian ini juga didukung oleh pernyataan petugas pemeriksa pajak di KPP Pratama Makassar Utara yang mengatakan bahwa dalam melakukan pemeriksaan pajak terhadap Wajib Pajak, sebagian besar dari mereka sudah patuh dalam mengisi (SPT) yang dilaporkan dan cukup cooperatif.

Dalam menjalankan tugasnya, pemeriksa pajak dituntut untuk meningkatkan kuantitas dan kualitas atas hasil kerjanya. Dalam hal ini seberapa banyak pemeriksa pajak telah menerbitkan SKP (Surat Ketetapan Pajak) dari hasil pemeriksaannya tersebut, dan dari SKP tersebut seberapa banyak tunggakan atau utang pajak yang dapat ditagih atau dicairkan. Jika SKP yang diterbitkan semakin banyak, maka pelaksanaan penagihan pajak kepada wajib pajak orang pribadi maupun badan akan semakin meningkat. Oleh karena itu, maka mutlak diperlukan tenaga pemeriksa pajak dalam kuantitas dan kualitas yang memadai. Jumlah pemeriksaan yang dilakukan dirjen pajak sebaiknya lebih memperhatikan kualitas dari pemeriksaan yang objektif dan pemeriksaan yang dapat memberikan hasil yang signifikan terhadap penerimaan pajak, maka dari itu diharapkan bagi aparat perpajakan untuk dapat meningkatkan kualitas pemeriksaan antara lain dengan cara penambahan jumlah petugas pajak yang melakukan pemeriksaan pajak dan peningkatan kuantitas dan kualitas mereka secara teknis baik secara akuntansi maupun mengenai peraturan perpajakan dalam melaksanakan pemeriksaan pajak.

Sedangkan untuk mendapatkan jaminan mutu atas hasil kerja pemeriksaan selain diperlukan kuantitas dan kualitas yang memadai, diperlukan juga prosedur pemeriksaan serta norma yang mengatur seorang pemeriksa pajak, agar tidak terjadi pemeriksaan yang bermasalah. Karena 
apabila terdapat pemeriksaan yang bermasalah, biasanya akan menimbulkan permasalahan pula dalam penagihannya. Untuk mengatasi kemungkinan terjadinya pemeriksaan dan penagihan yang bermasalah, KPP Pratama di wilayah Makassar Utara selalu mengevaluasi terhadap semua faktor-faktor pemeriksaan secara berkala dengan pengawasan yang baik.

Peran pemeriksaan sebagai pendongkrak penerimaan pajak mengharuskan adanya pengawasan yang efektif terhadap pelaksanaan pemeriksaan pajak. Pengawasan atau pengendalian intern terhadap pemeriksaan pajak ini diimplementasikan dalam bentuk administrasi dan monitoring terhadap pemeriksaan pajak. Pemeriksaan pajak juga bertujuan untuk meredam kecurangan yang dilakukan wajib pajak untuk meminimalkan pajaknya. Dalam rangka pemenuhan hak dan kewajiban perpajakan wajib pajak, DJP melakukan pemeriksaan rutin kepada wajib pajak. Apabila telah dilakukan pemeriksaan dengan baik maka akan berdampak pada peningkatan penerimaan pajak negara.

Hasil penelitian ini sejalan dengan penelitian yang dilakukan oleh Corry H (2010) yang menyatakan bahwa terdapat hubungan yang positif namun tidak signifikan antara pemeriksaan pajak dengan penerimaan pajak.

\section{KESIMPULAN}

\section{Kesimpulan}

Berdasarkan pada data yang telah dikumpulkan dan pengujian yang telah dilakukan terhadap permasalahan dengan menggunakan model regresi maka dapat disimpulkan bahwa pemeriksaan pajak berpengaruh positif namun tidak signifikan terhadap penerimaan pajak.

\section{DAFTAR PUSTAKA}

Alhusna, Riza. Tristini, Kiswanto Faktor-Faktor Yang Mempengaruhi Penerimaan Pajak, (Studi Kasus di KPP Semarang Tengah) Jurnal Akuntansi 2014

Corry H, Renold. Analisa Pengaruh Pemeriksaan Pajak Terhadap Penerimaan Pajak Di Kantor Pelayanan Pajak (KPP) Pratama Medan Kota Jurnal Akuntansi 2010 
Casavera. Perpajakan, Cetakan Pertama, Graha Ilmu, Yogyakarta, 2009.

Diana, Anastasia dan Lilis Setiawati. Perpajakan Indonesia, Edisi kedua, ANDI, Yogyakarta, 2009.

Febrianti, Irna.Pengaruh Kewajiban Kepemilikan NPWP, Pemeriksaan Pajak dan Penagihan Pajak Terhadap Penerimaan Pajak, (Studi kasus di KPP Jakarta Selatan), Jurnal Akuntansi Universitas Islam Negeri Syarif Hidatullah Jakarta,2013.

Fitriyani, Dewi dan Wiwik Tiswiyanti. Penerapan UU PPh No. 36 Tahun 2008: Manfaat dan Implikasi Bagi Wajib Pajak Pribadi, Jurnal Cakrawala Akuntansi, Vol.1, No.1, 2009.

Fouktone. Optimalisasi Penerimaan Pajak Melalui Pembenahan Sistem Administrasi Pajak. 2007.

Ghozali, Imam. Aplikasi Analisis Multivariate Dengan Program IBM SPSS 19, Edisi Ketiga, Badan Penerbit Universitas Diponegoro, Semarang, 2011.

Hamid, Abdul. PanduanPenulisanSkripsi, Cetakan 1, FEIS UIN Press, Jakarta, 2007.

Listyaningtyas, Ellya Florentin. Efektivitas Pelaksanaan Pemeriksaan Dalam Rangka Meningkatkan Penerimaan Negara dari SektorPajak (Studi kasus di KPP Tulungagung), Surabaya, 2012.

Mardiasmo, "Perpajakan”, EdisiRevisi, Andi, Yogyakarta, 2009.

Munari.Pengaruh Tax Payer terhadap Keberhasilan Penerimaan Pajak Penghasilan (Studi Kasus KPP Yogyakarta Satu). Jurnal Eksekutif Vol.2, No.2, Agustus 2005.

Pardiat. Pemeriksaan Pajak, Edisi Kedua, Mitra Wacana Media, Jakarta, 2008.

Prastowo, Yustinus. Panduan Lengkap Pajak, Raih Asa sukses, Jakarta, 2009.

Priantara, Diaz. Pemeriksaan dan PenyidikanPajak, Djambatan, Jakarta, 2002.

Priyatno, Duwi. Mandiri Belajar Analisis Data dengan SPSS, Yogyakarta: Media Kom, 2013

Purba, Arifanda. Analisis Hasil Pemeriksaan Pajak Tahun 2008-2011 untuk Menentukan Pola Profil wajib pajak Badan yang Potensial di Kantor 
Pelayanan Pajak Pratama Jakarta Palmerah, Tesis Fakultas Ekonomi Universitas Indonesia, 2012.

Rahayu, Dwi. Analisis Pengaruh Pemeriksaan Pajak Terhadap Kepatuhan Wajib Pajak, (Studi kasus pada KPP Semarang Selatan) Jurnal Akuntansi 2012

Rahayu, Siti Kurnia. Perpajakan Indonesia (Konsep dan Aspek Sosial), Cetakan Pertama, Graha Ilmu, Yogyakarta, 2010.

Resmi, Siti. Perpajakan: Teori dan Kasus, Edisi Kelima, Salemba Empat, Jakarta, 2009.

Salip dan Tendy Wato. Pengaruh Pemeriksaan Pajak Terhadap Penerimaan Pajak (Studi Kasus: Di KPP Jakarta Kebon Jeruk), Jurnal Keuangan Publik, Vol.4, No.2, September 2006.

Setiawan, Deddy Arief. Analisis Hubungan antara Ekstensifikasi Wajib Pajak dan Surat Setoran Pajak dengan PenerimaanPajak (Studi kasus pada KPP Jakarta Palmerah), Media Riset Akuntansi, Auditing dan Informasi, Vol.7, No.1, April 2007.

Suandy, Early. Perpajakan Salemba Empat, Jakarta, 2008.

Sugiyono. Metode Penelitian Bisnis, Cetakan ke-13, Alfabetacv, Bandung, 2009.

Sukirman. Pengaruh Manajemen Pemeriksaan Pajak terhadap Penerimaan Pajak, Analisis Manajemen, Vol.5, No.1, Juli 2011.

Sumarsan, Thomas. Perpajakan Indonesia (Pedoman Perpajakan yang Lengkap Berdasarkan Undang-undang Terbaru), Indeks, Jakarta, 2010.

Suryadi. Model Hubungan Kausa Kesadaran, Pelayanan, Kepatuhan Wajib Pajak dan Pengaruhnya terhadap Kinerja Penerimaan Pajak: Suatu Survei di Wilayah Jawa Timur, Vol.4, No.1, April 2006.

Tansuria, Billy Ivan. Pokok-pokok Ketentuan Umum Perpajakan (KUP), Cetakan Pertama, Graha IImu, Yogyakarta, 2010.

Umar, Husein. Riset Sumber Daya Manusia Dalam Organisasi (Edisi Revisi dan Perluasan), Gramedia Pustaka Utama, Jakarta, 2005.

Undang-undang Nomor 28 Tahun 2007 tentang Ketentuan Umum dan Tata Cara Perpajakan.

Wahyuni, Nur Indah. Dampak e-commerce dan Pemeriksaan Pajak Terhadap Penerimaan Pajak Pada KPP Pratama Kota Bandung, 
Jurnal Akuntansi 20013

Wildanishri, Pengaruh Pemeriksaan Pajak dan Surat Paksa Terhadap Penerimaan Pajak Penghasilan, (Studi Kasus Pada KPP Ciamis) Jurnal Akuntansi 2010

Waluyo, Perpajakan Indonesia, Salemba Empat, Jakarta, 2009.

Watini, Sri dan Ita Salsalina Lingga. Pengaruh Pemungutan Pajak Reklame Terhadap Penerimaan Pajak Daerah Kota Bandung, Jurnal Akuntansi, Vol.2 No.2, 2010. 